\title{
Pemanfaatan Kain Perca Di Kelurahan Tangkerang Timur, Kecamatan Tenayan Raya, Pekanbaru
}

\author{
ZAHARMAN $^{1}$; SERLY NOVIANTI ${ }^{2} ;$ ARINI $^{3}$ \\ Universitas Lancang Kuning \\ Jln. Yos Sudarso KM 08 Rumbai Telp. (0761) 52581 \\ E-mail : zaharman@unilak.ac.id
}

\begin{abstract}
The Community Service activity aims to provide knowledge to partners, namely the Ambonese craftsmen, precisely at RT 001 RW 004, how to improve understanding and knowledge about making sewing skills, as well as using patchwork, which was carried out at the East Tangkerang Sub-District, Tenayan Raya Pekanbaru District. The method of community service activities uses a direct practice method of using patchwork and giving motivation to creativity to Ambonese craftsmen. Practice is done by providing a direct example in making footwear. The expectation of the implementation of this service is the growth of creativity from Ambonese craftsmen in using lots of patchwork around us, so that the dedication that is directly done by Ambonese mothers can generate their own income and increase the economy in the household.
\end{abstract}

Keywords: Increased Knowledge, Utilization of Patchwork, Footwear

Kelurahan tangkerang timur kecamatan tenayan raya adalah pemukiman yang berpotensi sekali dalam pengembangan dan pengolahan kain perca. Karena banyaknya jumlah penjahit yang berada disekitar daerah tersebut, sehingga banyak pula peluang yang bisa diambil dalam memanfaatkan kain perca yang sudah tidak digunakan lagi. Dan itu merupakan peluang kerja maupun usaha yang bisa dimanfaatkan ibu-ibu di RT 004 RW 002.

Banyaknya kain perca yang terbuang dari 20 penjahit yang ada disekitar kelurahan tangkerang timur kecamatan tenayan raya, khususnya di RT 004 RW 002 menyebabkan limbah pakaian ini menjadi sampah yang hanya terbuang siasia. Padahal kalo kita lihat potensi yang ada banyak sekali yang dapat di manfaatkan dari kain perca itu sendiri. Contonya seperti : bros jilbab, keset kaki, tas, boneka, alas mejatatakan gelas, kotak tisu, hiasan bahkan selimut. Aktivitas yang paling cocok sekali bagi kaum wanita yang mempunyai banyak waktu luang dirumah.

Kalo dilihat dari segi perekonomian disekitar kelurahan tangkerang timur kecamatan tenayan raya, khususnya di RT 004 RW 002 bisa dikatakan masih banyak kalangan yang kurang mampu dalam memenuhi kebutuhan sehari-hari mereka. Karena dilingkungan tersebut masih banyak suami (pemimpin keluarga) yang kerjanya serabutan dan tidak berpenghasilan tetap dalam setiap hari bahkan bulannya. Untuk menutupi kekurangan dalam kebutuhan sehari-hari mereka, bahkan ibu-ibunya juga rela berkorban bekerja menjadi pembantu rumah tangga dari rumah ke rumah, tukang urut panggilan, dan banyak lagi. Semua itu mereka lakukan untuk memenuhi kebutuhan sehari-hari yang tidak tercukupi. Ditambah lagi perlunya biaya untuk anak-anak yang masih dalam dunia pendidikan dasar.

Kalau dilihat dari segi perekonomian disekitar kelurahan tangkerang timur kecamatan tenayan raya, khususnya di RT 004 RW 002 bisa dikatakan masih banyak kalangan yang kurang mampu dalam memenuhi kebutuhan sehari-hari mereka. Karena dilingkungan tersebut masih banyak suami (pemimpin keluarga) yang kerjanya serabutan dan tidak berpenghasilan tetap dalam setiap hari bahkan bulannya. Untuk menutupi kekurangan dalam kebutuhan 
sehari-hari mereka, bahkan ibu-ibunya juga rela berkorban bekerja menjadi pembantu rumah tangga dari rumah ke rumah, tukang urut panggilan, dan banyak lagi. Semua itu mereka lakukan untuk memenuhi kebutuhan sehari-hari yang tidak tercukupi. Ditambah lagi perlunya biaya untuk anakanak yang masih dalam dunia pendidikan dasar.

Sebelumnya ibu-ibu pengrajin ambon ini sudah memiliki hasil dari olahan limbah kain perca yaitu bros jilbab. Yang langsung dapat di order sesuai permintaan konsumen, biasanya disaat permintaan pesta pernikahan. Tapi lambat laun seiring berjalannya waktu peminat serta kemauan ibu-ibu pengrajin ini mulai kendur. Mungkin salah satu penyebabnya adalah kurangnya motivasi baik dari dalam diri maupun dukungan motivasi yang didapat ibu-ibu pengrajin ambon.

Dan sekarang ini, ibu-ibu pengrajin ambon sudah mulai tidak ada ide dan kurang tertarik dalam pengembangan produk yang sudah ada. Yaitu membuat bros jilbab. Sehingga dari permasalah yang ditimbulkan ini kami bergabung ke ibu-ibu pengrajin ambon ini, berharap kerajinan tangan dari pemanfaatan kain perca ini tetap terus berjalan. Kami ingin memberikan motivasi dan bisa berbagi pengalaman serta wawasan yang kami miliki untuk kita kembangkan bersama dalam pemanfaatan kain perca dan apa saja yang bisa diolah lagi selain bros jilbab. Bukan sekedar memberikan motivasi tapi kami berkeingin usaha yang sudah ada bisa berkembang lagi dengan berbagai macam kreasi yang bermanfaat dari pemanfaatan kain perca.

Banyaknya kesempatan dalam pemanfaatan kain perca, membuat ibu-ibu pengharajin ambon harus lebih kreatif lagi dan terus menambah ilmu pengetahuan tentang kebutuhan-kebutuhan apa saja yang bisa dimanfaatkan dari kain perca. Apalagi kalau mereka bisa melihat permintaan apa saja yang dapat diwujudkan dari lingkungan sekitar. Terutama dari hasil olahan kain perca ini. Sehingga dapat memberikan keanekaragaman dalam menghasilkan barang dari kain perca.

Dapat diperhatikan dari ketrampilan yang dimiliki, sebenarnya peluang keberhasilan cukup besar yang akan didapat ibu-ibu pengrajin Ambon. Apabila ibu-ibu bisa tetap konsisten terhadap usaha yang sudah berjalan, apalagi kalau ibu-ibu pengrajin ambon ini bisa menambah wawasannya dalam berkreasi dalam pemanfaatan limbah berupa kain perca ini. Oleh karena itu perlu dilaksanakan program pemanfaatan kain perca dan memberikan motivasi dalam pengembangan produk kepada ibuibu pengrajin ambon di kelurahan tangkerang timur, kecamatan tenayan raya, pekanbaru.

Dari permasalahan-permasalahan yang muncul sehingga kami berharap ibuibu pengrajin ambon ini bisa lebih produktif lagi. Dan mendapatkan tambahan penghasilan dari ketrampilan tangan yaitu pemanfaatan kain perca yang sudah tidak digunakan lagi. Program pengabdian bagi masyarakat yang telah diselenggarakan berdasarkan latar belakang di atas serta fokus permasalahan yang akan diprioritaskan untuk dipecahkan dalam kegiatan pengabdian masyarakat tersebut. Berdasarkan latar belakang tersebut, program pengabdian masyarakat ini dinamakan "Pemanfaatan Kain Perca Di Kelurahan Tangkerang Timur Kecamatan Tenayan Raya, Pekanbaru."

\section{METODE}

Metode yang akan dilakukan oleh tim selama kegiatan pengabdian bagi masyarakat dengan Mitra Kelompok ibuibu pengrajin Ambon di Kelurahan Tangkerang Timur Kecamatan Tenayan Raya Pekanbaru :

1. Untuk pengusaha mikro/jasa layanan.

a. Dalam permasalahan motivasi diri, minat dan bakat dari kelompok ibu-ibu pengrajin ambon. 
b. Dalam permasalahan hasil produksi yang kurang di kreasikan.

c. Dalam permasalahan ekonomi dari lingkungan sekitar.

Memberikan pengetahuan tentang mengembangkan minat dan bakat serta motivasi diri dalam pemanfaatan kain perca. Apalagi potensi dilingkungan sekitar yaitu banyaknya hasil olahan limbah berupa kain perca dan memberikan masukan dalam mengembangkan hasil olahan kain perca seperti bros jilbab, keset kaki, tas, boneka, alas meja, tatakan gelas, kotak tisu, hiasan bahkan selimut. Mempertahankan sumber penghasilan yang sudah terbentuk, serta memberikan contoh langsung dalam pemanfaatan kain perca yaitu Praktik langsung dalam pembuatan keset kaki. Sehingga dapat menghasilkan kelompok ibuibu pengrajin ambon yang produktif.

\section{HASIL}

Hasil yang diperoleh dari penyebaran kuesioner kepada 15 orang peserta sebelum dan sesudah pelatihan dilaksanakan adalah sebagai berikut :

Tabel 1. Hasil Penyebaran kuesioner sebelum dan sesudah kegiatan

\begin{tabular}{|l|l|l|l|l|l|l|}
\hline \multirow{2}{*}{ Pertanyaan } & \multicolumn{3}{|c|}{$\begin{array}{c}\text { Jawaban } \\
\text { sebelum } \\
\text { Pelatihan }\end{array}$} & \multicolumn{3}{c|}{$\begin{array}{c}\text { Jawaban } \\
\text { sesudah } \\
\text { Pelatihan }\end{array}$} \\
\cline { 2 - 7 } & Y & R & K & Y & R & K \\
\hline $\begin{array}{l}\text { Apakah saudara pernah } \\
\text { mengolah limbah kain } \\
\text { perca }\end{array}$ & 12 & 0 & 3 & 12 & 0 & 3 \\
\hline $\begin{array}{l}\text { Apakah saudara pernah } \\
\text { mengikuti pelatihan } \\
\text { mengenai pemanfaatan } \\
\text { kain perca }\end{array}$ & 5 & 0 & 10 & 15 & 0 & 0 \\
\hline $\begin{array}{l}\text { Apakah saudara } \\
\text { memiliki minat untuk } \\
\text { mengolah kain perca }\end{array}$ & 8 & 5 & 2 & 15 & 0 & 0 \\
\hline $\begin{array}{l}\text { Apakah saudara ada } \\
\text { keinginan untuk } \\
\text { memproduksikannya } \\
\text { untuk penjualan }\end{array}$ & 8 & 5 & 2 & 15 & 0 & 0 \\
\hline $\begin{array}{l}\text { Apakah saudara } \\
\text { mengerti bagaimana } \\
\text { cara membuat alas kaki } \\
\text { dari awal sampai }\end{array}$ & 0 & 3 & 12 & 14 & 0 & 1 \\
\hline
\end{tabular}

\begin{tabular}{|l|c|c|c|c|c|c|}
\hline \multirow{2}{*}{\multicolumn{1}{|c|}{ Pertanyaan }} & \multicolumn{3}{c|}{$\begin{array}{c}\text { Jawaban } \\
\text { sebelum } \\
\text { Pelatihan }\end{array}$} & \multicolumn{3}{c|}{$\begin{array}{c}\text { Jawaban } \\
\text { sesudah } \\
\text { Pelatihan }\end{array}$} \\
\cline { 2 - 7 } & $\mathrm{Y}$ & $\mathrm{R}$ & $\mathrm{K}$ & $\mathrm{Y}$ & $\mathrm{R}$ & $\mathrm{K}$ \\
\hline dengan selesai & & & & & & \\
\hline $\begin{array}{l}\text { Apakah saudara puas } \\
\text { dengan hasil olahan } \\
\text { kain perca yang } \\
\text { dihasilkan (alas kaki) }\end{array}$ & 8 & 5 & 2 & 15 & 0 & 0 \\
\hline $\begin{array}{l}\text { Apakah ada kendala } \\
\text { yang dihadapi dalam } \\
\text { mengikuti praktek } \\
\text { pembuatan alas kaki }\end{array}$ & 13 & 1 & 1 & 1 & 0 & 14 \\
\hline $\begin{array}{l}\text { Apakah ada kerjasama } \\
\text { yang baikantar } \\
\text { anggota kelompok }\end{array}$ & 13 & 2 & 0 & 15 & 0 & 0 \\
\hline
\end{tabular}

Ket:

$\mathrm{Y}=\mathrm{Ya}$

$\mathrm{K}=$ Kurang

$\mathrm{R}=$ Ragu-ragu

Berdasarkan hasil rangkuman kuesioner diatas, terdapat perbedaan pengetahuan dan keterampilan peserta pelatihan sebelum dan sesudah kegiatan ini. Peserta pelatihan sudah mengetahui pemanfaatan kain perca.Selain itu sebagian besar peserta tertarik untuk mempraktekkan kembali dan bersemangat ingin memperbanyak hasil oalahan limbah kain perca berupa alas kaki tersebut.

\section{PEMBAHASAN}

Metode yang akan dilakukan oleh tim selama kegiatan pengabdian bagi masyarakat dengan Mitra Kelompok ibuibu pengrajin Ambon di Kelurahan Tangkerang Timur Kecamatan Tenayan Raya Pekanbaru : Untuk pengusaha mikro/jasa layanan.

a. Dalam permasalahan motivasi diri, minat dan bakat dari kelompok ibu-ibu pengrajin ambon.

b. Dalam permasalahan hasil produksi yang kurang di kreasikan.

c. Dalam permasalahan ekonomi dari lingkungan sekitar.

Memberikan pengetahuan tentang mengembangkan minat dan bakat serta motivasi diri dalam pemanfaatan kain 
perca. Apalagi potensi dilingkungan sekitar yaitu banyaknya hasil olahan limbah berupa kain perca dan memberikan masukan dalam mengembangkan hasil olahan kain perca seperti bros jilbab, keset kaki, tas, boneka, alas meja, tatakan gelas, kotak tisu, hiasan bahkan selimut. Mempertahankan sumber penghasilan yang sudah terbentuk, serta memberikan contoh langsung dalam pemanfaatan kain perca yaitu Praktik langsung dalam pembuatan keset kaki. Sehingga dapat menghasilkan kelompok ibuibu pengrajin ambon yang produktif.

\section{SIMPULAN}

Kesimpulan dari pelaksanaan kegiatan ini adalah: Peserta pelatihan dapat memiliki pengetahuan tentang bagaimana cara mengolah limbah kain perca. Peserta pelatihan dapat mengolah kain perca menjadi alas kaki yang berbagai bentuk. Seperti : oval, persegi panjang dan bulat. Peserta pelatihan memiliki minat yang tinggi terhadap hasil olahan limbah kain perca yang diolah.

Berdasarkan kesimpulan diatas dapat dibuat saran sebagai berikut: Peserta diharapkan terus semangat dalam mengolah bahan limbah kain perca dan menjaga kerjasama kelopok yang baik agar terus dapat mengembangkan hasil olahan limbah agar dapat dipasarkan ke luar daerah atau kota. Peserta pelatihan perlu senantiasa mengembangkan pengetahuan dan berinovasi dalam mengolah limbah kain perca sehingga bisa tetap diterima konsumen.

\section{DAFTAR RUJUKAN}

Iwanto, S. 2003. Kiat Sukses Berwirausaha. Pt Grasindo. Jakarta

Manurung, A. H. 2005. Wirausaha Bisnis UKM. PT kompas Media Nusantara. Jakarta

Meredith and G, G. Et all. 2000. Kewirausahaan: Teori dan praktek. CV Taruna Grafica. Jakarta.
Rochaety, E dan Tresnaty, R. Madjid Latief, A.2007.Metodologi Penelitian Bisnis: Dengan Aplikasi SPSS.Mitra Wacana Media. Jakarta.

Sarosa, P. 2003. Kiat Praktis Membuka Usaha. Pt Elex Media Komputindo. Jakarta.

Sugiyono, dan Wibowo, E. 2004.Statistika untuk Penelitian dan Aplikasinya dengan SPSS ver 10.0 For Windows.Alfabeta. Bandung.

Suryana. 2006. Kewirausahaan. Salemba Empat. Jakarta.

Agustina,L. 2012. Modul Pelajaran Menjahit Pakaian Wanita Tingkat Dasar. Bandung.

Sean, Sally. 2006. Pemanfaatan Kain Perca. ITB. Bandung. 